\title{
Protective effects of hydrogen sulfide on oxidative stress and fibrosis in hepatic stellate cells
}

\author{
HAI-NING FAN, HAI-JIU WANG, CAI-RANG YANG-DAN, LI REN, \\ CONG WANG, YAN-FEI LI and YONG DENG \\ Department of Hepatopancreatobiliary Surgery, Affiliated Hospital of Qinghai University, \\ Xining, Qinghai 810001, P.R. China
}

Received May 18, 2012; Accepted September 11, 2012

DOI: $10.3892 / \mathrm{mmr} .2012 .1153$

\begin{abstract}
In hepatic fibrosis, hepatic stellate cells (HSCs) are activated and change into myofibroblast-like cells which are characterized by increased proliferation and extracellular matrix (ECM) synthesis. In this study, we investigated the regulatory effects of hydrogen sulfide $\left(\mathrm{H}_{2} \mathrm{~S}\right)$ on hepatic fibrosis. We detected the proliferation, cell cycle progression, apoptosis, intracellular reactive oxygen species (ROS) and free calcium levels in ferric nitrilotriacetate (Fe-NTA)-activated HSCs treated with sodium hydrogen sulphide (NaHS), an $\mathrm{H}_{2} \mathrm{~S}$-releasing molecule. We also evaluated the effects of NaHS on fibrosis and ECM synthesis in rats with hepatic fibrosis induced by carbon tetrachloride (CCl4). MTT assay revealed that NaHS $(500 \mu \mathrm{mol} / \mathrm{l})$ suppressed the Fe-NTA-induced proliferation of HSC-T6 cells in a dose-dependent manner. NaHS induced G1 phase cell cycle arrest and apoptosis in the Fe-NTA-treated HSC-T6 cells. Furthermore, in the Fe-NTAtreated HSC-T6 cells, NaHS reduced intracellular levels of ROS at 1,3 and $6 \mathrm{~h}$ and reduced intracellular free calcium levels at 3 and 6 h. $\mathrm{H}_{2} \mathrm{~S}$ administration attenuated hepatic fibrosis and collagen $\mathrm{I}$ protein expression in the rats with $\mathrm{CCl}_{4}$-induced hepatic fibrosis. In conclusion, exogenous $\mathrm{H}_{2} \mathrm{~S}$ inhibits proliferation and induces cell cycle arrest and apoptosis in activated $\mathrm{HSCs}$ and attenuates $\mathrm{CCl}_{4}$-induced hepatic fibrosis and ECM expression.
\end{abstract}

\section{Introduction}

Hepatic fibrosis is caused by the destruction of the architecture of the liver parenchyma and is a common wound-healing response to hepatic diseases, including chronic hepatitis and liver damage, which forms scars or fibrous tissues through excessive fibrogenesis and insufficient fibrolysis. Hepatic stellate cells (HSCs) are

Correspondence to: Dr Yong Deng, Department of Hepatopancreatobiliary Surgery, Affiliated Hospital of Qinghai University, 29 Tongren Road, Xining, Qinghai 810001, P.R. China

E-mail: dengyqh@163.com

Key words: hepatic fibrosis, hepatic stellate cells, hydrogen sulfide, collagen I, extracellular matrix crucial to the development of hepatic fibrosis (1). During hepatic fibrosis, HSCs are activated and change into myofibroblastlike cells, which are characterized by increased proliferation and extracellular matrix (ECM) synthesis (2). Fibrogenesis is promoted by the activation and proliferation of HSCs and delayed by the apoptosis of HSCs. Current antifibrosis strategies include inhibition of the activation and proliferation of HSCs and induction of the apoptosis of activated HSCs (3). HSCs are considered to be an attractive target in antifibrosis strategies due to their essential role in hepatic fibrosis.

Hydrogen sulfide $\left(\mathrm{H}_{2} \mathrm{~S}\right)$ is a gaseous messenger that displays many physiological and pathological activities (4). The administration of $\mathrm{H}_{2} \mathrm{~S}$ has been reported to attenuate myocardial infarct size (5), suppress the development of hypertension (6) and alleviate neuronal injury (7). The mechanisms underlying the action of $\mathrm{H}_{2} \mathrm{~S}$ predominantly involve the inhibition of oxidative stress and inflammatory responses and the activation of ATP-sensitive potassium (KATP) channels (4).

$\mathrm{H}_{2} \mathrm{~S}$ plays a regulatory role in hepatic physiology and pathology (8). In mammalian hepatic tissues, $\mathrm{H}_{2} \mathrm{~S}$ is mainly produced by cystathionine c-lyase (CSE) (9), and activates KATP channels, leading to vasorelaxation of the hepatic artery (10). Since hepatic cirrhosis is associated with the development of a hyperdynamic circulation caused by systemic vasodilation, it has been postulated that $\mathrm{H}_{2} \mathrm{~S}$ is involved in the pathogenesis of the vascular abnormalities in cirrhosis (11). $\mathrm{H}_{2} \mathrm{~S}$ displays antioxidative, anti-inflammatory and cytoprotective activities; therefore, we hypothesized that $\mathrm{H}_{2} \mathrm{~S}$ may have a protective effect against hepatic fibrosis.

The present study aimed to investigate the effects of sodium hydrogen sulphide ( $\mathrm{NaHS}$ ), an $\mathrm{H}_{2} \mathrm{~S}$-releasing molecule, on the proliferation, cell cycle, apoptosis, intracellular reactive oxygen species (ROS) and free calcium levels of activated HSC cells, and on fibrosis and ECM synthesis in rats with carbon tetrachloride $\left(\mathrm{CCl}_{4}\right)$-induced hepatic fibrosis.

\section{Materials and methods}

Cell culture. The rat HSC line (HSC-T6) was purchased from the Institute of Biochemistry and Cell Biology, Shanghai Institutes for Biological Sciences, Chinese Academy of Sciences (Shanghai, China). The cells were cultured in DMEM (Invitrogen-Gibco, Carlsbad, CA, USA), supplemented with $10 \%$ 
fetal bovine serum (FBS) (Sijichun Bioengineering Materials, Inc., Hangzhou, China), $100 \mathrm{U} / \mathrm{ml}$ penicillin and $100 \mu \mathrm{g} / \mathrm{ml}$ streptomycin, at $37^{\circ} \mathrm{C}$ in a humidified incubator with $5 \% \mathrm{CO}_{2}$.

Cell viability assay. The cell growth rate was determined by MTT (Sigma-Aldrich, St. Louis, MO, USA) assay. Briefly, cells at the logarithmic growth phase were seeded in 96-well culture plates at a density of $1 \times 10^{3}$ cell $/ \mathrm{ml}$ with $100 \mu \mathrm{l}$ per well. The cells were then cultured in DMEM and incubated with $500 \mu \mathrm{g} / 1$ ferric nitrilotriacetate (Fe-NTA) (Sigma-Aldrich) and various concentrations of NaHS (Sigma-Aldrich) (0, 100, 200 or $500 \mu \mathrm{mol} / \mathrm{l})$ for $24 \mathrm{~h}$. For the cell viability assay, $10 \mu \mathrm{l} \mathrm{MTT}$ solution $(5 \mathrm{mg} / \mathrm{ml})$ was added to each well and the plates were incubated at $37^{\circ} \mathrm{C}$ for $4 \mathrm{~h}$. After centrifugation at $3,000 \mathrm{rpm}$ for $10 \mathrm{~min}$, the supernatant was removed and the formazan pellet was dissolved completely in $100 \mu \mathrm{l}$ DMSO. The absorbance was measured with an ELISA plate reader at a wavelength of $570 \mathrm{~nm}$ to determine the amount of viable cells in the pellet.

Cell cycle analysis. The cells were harvested by trypsinization, centrifuged at 2,000 rpm for $5 \mathrm{~min}$, washed with PBS and resuspended in cold $70 \%$ ethanol. Finally, $1 \mathrm{ml}$ propidium iodide (PI) staining solution (PI, $20 \mu \mathrm{g} / \mathrm{ml}$; DNase free RNase A, $100 \mu \mathrm{g} / \mathrm{ml}$ ) was added to the samples which were analyzed using a FACScan (BD Biosciences, San Francisco, CA, USA) within $30 \mathrm{~min}$. Data on 10,000 cells were acquired and processed using Lysis II software (BD Biosciences).

Cell apoptosis assay. Cells at the logarithmic growth phase were randomly divided into 4 groups: the normal control, NaHS (500 $\mu \mathrm{mol} / \mathrm{l}), \mathrm{Fe}-\mathrm{NTA}(500 \mu \mathrm{g} / \mathrm{l})$ and Fe-NTA + NaHS groups After $24 \mathrm{~h}, 2 \times 10^{5}$ cells were collected from each group and washed with phosphate-buffered saline (PBS). The pellet was resuspended in $100 \mu 1 \mathrm{X}$ binding buffer and combined with $2.5 \mu \mathrm{l}$ Annexin V and $5 \mu \mathrm{l}$ PI (final concentration, $10 \mu \mathrm{g} / \mathrm{ml}$ ), followed by incubation for $15 \mathrm{~min}$ in the dark. Apoptosis was determined by flow cytometry. At least 10,000 events were analyzed for each sample. The data were analyzed using Lysis software.

Measurement of ROS generation. Intracellular ROS was quantified with a fluorescence plate reader using 2,7-dichlorodihydrofluorescein diacetate (DCFH-DA, Sigma-Aldrich). The cells on 96-well plates were treated with NaHS $(500 \mu \mathrm{mol} / \mathrm{l})$ and/or Fe-NTA $(500 \mu \mathrm{g} / \mathrm{l})$ for 1,3 or $6 \mathrm{~h}$ and incubated with DCFH-DA at $37^{\circ} \mathrm{C}$ for $30 \mathrm{~min}$. Following the removal of the DCFH-DA, the cells were washed with PBS. The DCFH-DA-loaded cells were read using a fluorescence plate reader (Tecan, Crailsheim, Germany).

Measurement of intracellular free calcium $\left[\mathrm{Ca}^{2+}\right]_{i}$ Fura2-acetoxymethylester(Fura2-AM)(DojindoLaboratories, Kumamoto, Japan), a fluorescent $\mathrm{Ca}^{2+}$-sensitive dye, was used to monitor $\left[\mathrm{Ca}^{2+}\right]_{\mathrm{i}}$. The cells were cultured and treated with NaHS (500 $\mu \mathrm{mol} / 1)$ and/or Fe-NTA (500 $\mu \mathrm{g} / \mathrm{l})$ for 3 or $6 \mathrm{~h}$ and preloaded with $1 \mu \mathrm{mol} / 1$ Fura 2 -AM for $30 \mathrm{~min}$ in the dark at $37^{\circ} \mathrm{C}$ in a humidified incubator. After loading with Fura 2-AM, the cells were collected, washed 3 times with D-Hanks' solution and resuspended in D-Hanks' solution containing $0.2 \%$ $\mathrm{BSA}$ at $1 \times 10^{6}$ cells $/ \mathrm{ml}$. Fluorescence intensity was measured at an emission wavelength of $510 \mathrm{~nm}$ and excitation wavelengths of 340 and $380 \mathrm{~nm}$ using a Safire fluorescence plate reader (Tecan). $\left[\mathrm{Ca}^{2+}\right]_{\mathrm{i}}$ was estimated from the ratio of the fluorescence intensities at 340 and $380 \mathrm{~nm}$ (F340/F380).

Western blot analysis. HSC-T6 cells were cultured and treated with NaHS (500 $\mu \mathrm{mol} / \mathrm{l})$ and/or Fe-NTA (500 $\mu \mathrm{g} / \mathrm{l})$ for $24 \mathrm{~h}$. The proteins were isolated and their concentrations were determined. The proteins $(50 \mu \mathrm{g})$ were separated on sodium dodecyl sulfate polyacrylamide gel electrophoresis (SDS-PAGE) gels (polyacrylamide concentration $100 \mathrm{~g} / \mathrm{l}$ ) and electrophoretically transferred onto a PVDF membrane. The PVDF membrane was blocked with $3 \% \mathrm{BSA}$ at $37^{\circ} \mathrm{C}$ for $1 \mathrm{~h}$ and probed with the rabbit polyclonal antibody against collagen I $(1: 1,000)$ (Santa Cruz Biotechnology, Inc., Santa Cruz, CA, USA), followed by horseradish peroxidase-conjugated goat anti-rabbit IgG $(1: 1,000)$ for $2 \mathrm{~h}$ at room temperature. The densities of the targeted bands were visualized using the chemiluminescence method. $\beta$-actin was used as the internal control.

Animal model of hepatic fibrosis. All studies were approved by the Animal Study Committee of the Qinghai University School of Medicine. Male Wistar rats (weighing 220-240 g) were supplied by the Animal Research Center at the Affiliated Hospital of Qinghai University. They were maintained on standard laboratory rat chow on a 12-h light/dark cycle at a temperature of $22-23^{\circ} \mathrm{C}$. Liver fibrosis was induced by carbon tetrachloride $\left(\mathrm{CCl}_{4}\right)$ injection. Briefly, phenobarbital sodium $(0.35 \mathrm{~g} / \mathrm{l})$ was administered to the rats with their drinking water for 3 days. This was followed by an intraperitoneal injection of $100 \mu \mathrm{l} \mathrm{Cl}_{4} / 100 \mathrm{~g}$ body weight in an equal volume of paraffin oil twice a week for 6 weeks. Rats receiving an intraperitoneal injection of $100 \mu \mathrm{l}$ of saline/100 g body weight in an equal volume of paraffin oil were used as the control group.

Animal grouping and experiment. A total of 24 rats with liver fibrosis receiving $\mathrm{CCl}_{4}$ injections for 6 weeks were randomly assigned into 2 groups (each of 12 rats), and an intraperitoneal injection of $1 \mathrm{ml}$ saline or NaHS solution $(10 \mathrm{mmol} / \mathrm{kg}$ body weight) was administered every 2 days for 6 weeks. The 12 rats in the control group received an intraperitoneal injection of $1 \mathrm{ml}$ saline for every 2 days for 6 weeks. At the completion of the experiments, the rats were sacrificed for pathological examination. Blood was collected via cardiac puncture and then the liver tissue was collected. Serum and liver samples were prepared and stored at $4^{\circ} \mathrm{C}$.

Histological analysis. Formalin-fixed liver specimens were embedded in paraffin, sectioned, stained with hematoxylin and eosin (H\&E) and examined under a light microscope. Cell numbers were quantified by measuring the numbers of blue pixels in the images captured from the H\&E-stained sections. Ten images (magnification, x400) were randomly captured from each liver using a fixed exposure time and conditions. The images were saved as Joint Photographic Experts Group (JPEG) files and the numbers of blue pixels were counted using the histogram function in Adobe Photoshop CS4.

Immunohistochemistry analysis. Liver sections $(5 \mathrm{~mm}$ in thickness) were incubated at $4^{\circ} \mathrm{C}$ overnight with a primary antibody 
$\mathbf{A}$

Effect of NaHS on HSC-T6 cell proliferation

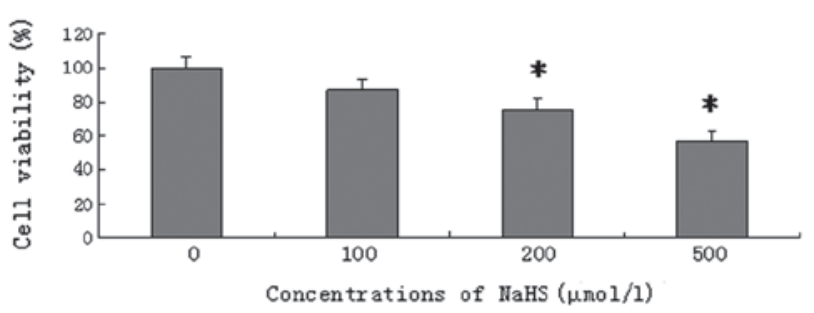

C

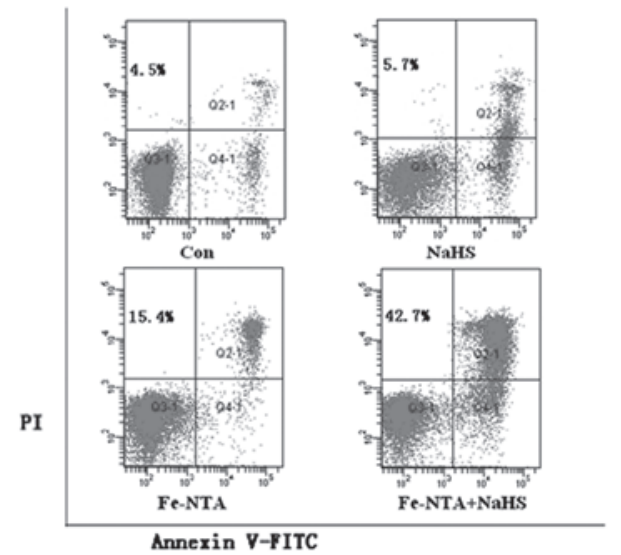

B Effect of NaHS on the cell cycle of Fe-NTA-induced HSCs

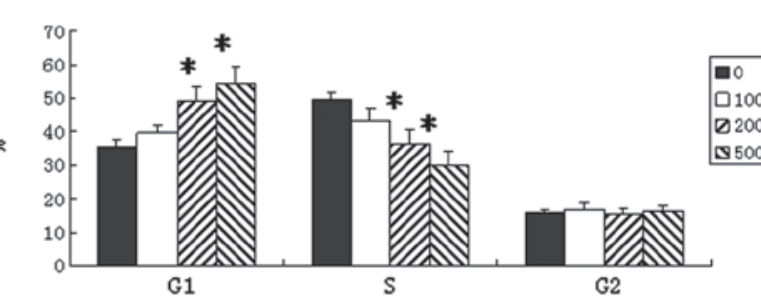

D

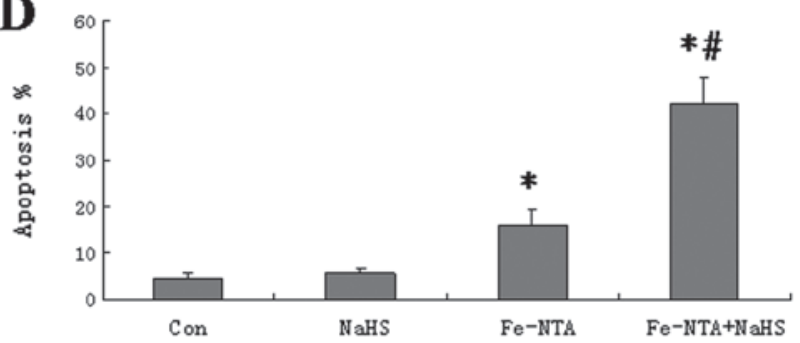

Figure 1. Effect of sodium hydrogen sulfide (NaHS) on the ferric nitrilotriacetate (Fe-NTA)-induced proliferation of HSC-T6 cells. Cells were seeded in 96-well culture plates and incubated with various concentrations of NaHS (0, 100, 200 or $500 \mu$ mol/1) for 24 h. (A) Cell proliferation was detected by MTT assay. Data are expressed as a percentage of the control and result from at least 3 independent experiments. (B) Propidium iodide (PI, 20 $\mu$ g/ml) staining was performed to determine the percentages of cells in the G1, S and G2 phases. (C) Cell apoptosis was determined by Annexin V-FITC and PI double staining using flow cytometry following $24 \mathrm{~h}$ of treatment. The NaHS treatment did not increase the apoptotic rate of the HSC-T6 cells. Fe-NTA increased the apoptotic rate of the HSC-T6 cells significantly $(\mathrm{P}<0.05)$ and this effect was further enhanced by NaHS. Representative images from three experiments are shown. (D) Apoptotic rates are shown for the control, NaHS, Fe-NTA and Fe-NTA+NaHS groups. Data are expressed as the means \pm SD and were compared using a two-tailed, unpaired t-test. "Significant difference from the control group $(\mathrm{P}<0.05)$. "Significant difference from the Fe-NTA group.

against collagen I (Santa Cruz Biotechnology, Inc.) at a concentration of 1:100. The secondary antibody was horseradish peroxidase-conjugated IgG (Medical Biological Laboratory, Nagoya, Japan) and was used for $30 \mathrm{~min}$ at $37^{\circ} \mathrm{C}$. After washing with Tris-buffered saline, the sections were incubated with complex/horseradish peroxidase (1:200 dilution) for $30 \mathrm{~min}$ at $37^{\circ} \mathrm{C}$. Immunolocalization was performed by immersion in $0.05 \%$ 3,3'-diaminobenzidine tetrahydrochloride as the chromagen. The slides were counterstained with hematoxylin prior to dehydration and mounting. Slides which did not undergo primary antibody incubation were processed as a control for the background staining. The brown positive cells throughout the entire section were counted and the total counts in these sections were converted into cell densities for quantification.

Statistical analysis. Statistical analysis was performed using commercially available software (SPSS version 14.0). Data are expressed as the means \pm standard deviation. The Student's t-test (unpaired, two-tailed) was performed to compare the means of 2 groups. $\mathrm{P}<0.05$ was considered as a statistically significant result.

\section{Results}

$\mathrm{H}_{2} \mathrm{~S}$ inhibits HSC proliferation. The HSC-T6 cells were stimulated by incubation with Fe-NTA $(500 \mu \mathrm{mol} / \mathrm{l})$. These cells were simultaneously treated with various concentrations of NaHS
$(0,100,200$ or $500 \mu \mathrm{mol} / \mathrm{l})$ for $24 \mathrm{~h}$. The MTT assay revealed that NaHS inhibited HSC proliferation in a dose-dependent manner. Cell viability was significantly reduced by the 200 and $500 \mu \mathrm{mol} / 1$ concentrations of NaHS (P<0.05; Fig. 1A).

$\mathrm{H}_{2} \mathrm{~S}$ induces $\mathrm{Gl}$ phase cell cycle arrest in HSCs. To clarify the possible mechanism behind the antiproliferative activity of NaHS, the cell cycle distribution in the Fe-NTA-activated cells was determined following treatment with $0,100,200$ or $500 \mu \mathrm{mol} / \mathrm{l} \mathrm{NaHS}$ for $24 \mathrm{~h}$. NaHS induced a significant increase in the number of cells in the G1 phase, with a corresponding decrease in the number of cells in the $S$ phase. However, no significant differences were found in the percentages of the cells in the G2 phase following NaHS treatment (Fig. 1B). These results indicate that NaHS inhibits HSC proliferation by inducing G1 phase arrest.

$\mathrm{H}_{2} \mathrm{~S}$ increases $\mathrm{Fe}$-NTA-induced apoptosis in HSCs. To investigate whether apoptosis is involved in the reduction in the number of viable cells when HSCs are treated with NaHS, the cells were cultivated in the presence of Fe-NTA and/or NaHS for $24 \mathrm{~h}$. Cell apoptosis was analyzed by Annexin V-FITC and PI double staining. NaHS treatment (500 $\mu \mathrm{mol} / \mathrm{l})$ alone did not increase the apoptotic rate. Fe-NTA increased the apoptotic rate of the HSCs moderately. However, treatment with Fe-NTA and NaHS resulted in a significantly higher apoptotic rate than treatment with Fe-NTA alone $(\mathrm{P}<0.05$; Fig. $1 \mathrm{C}$ and D). 
A

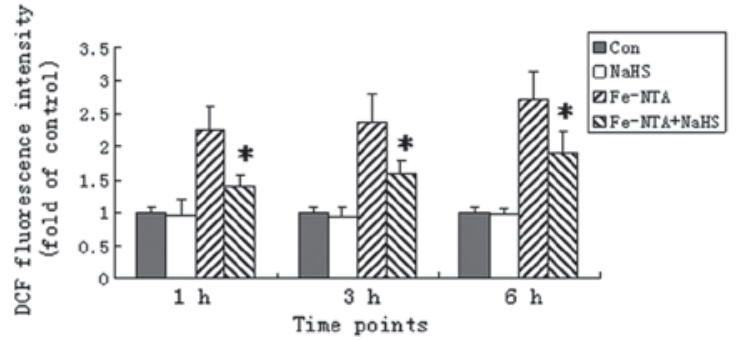

C

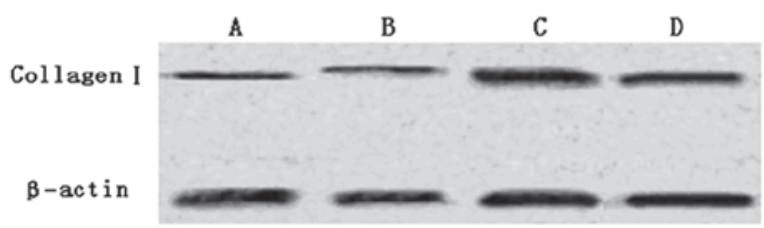

B

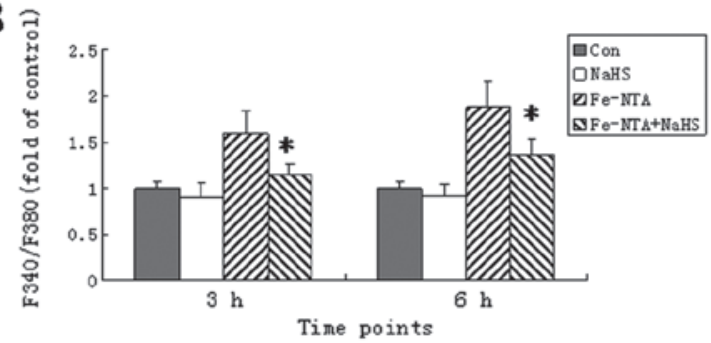

D

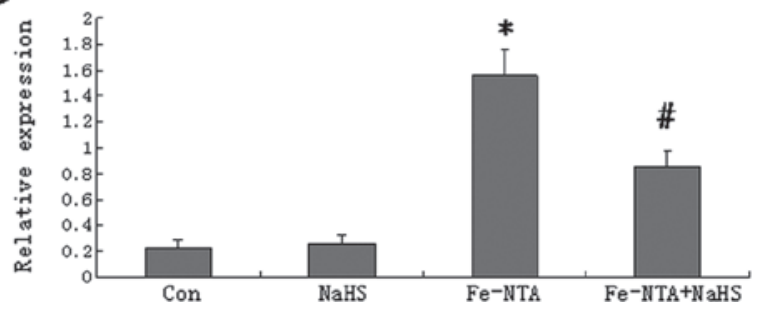

Figure 2. Sodium hydrogen sulfide (NaHS) decreased reactive oxygen species (ROS), intracellular $\mathrm{Ca}^{2+}\left[\mathrm{Ca}^{2+}\right]_{\mathrm{i}}$ and collagen I expression in ferric nitrilotriacetate (Fe-NTA)-treated HSC-T6 cells. (A) Cells were treated with Fe-NTA and/or NaHS for 1, 3 or 6 h, followed by a 30 -min incubation at $37^{\circ} \mathrm{C}$ for ROS detection using 2',7'-dichlorodihydrofluorescein diacetate (DCFH-DA). (B) Cells were treated with Fe-NTA and/or NaHS for 3 or 6 h. [Ca $\left.{ }^{2+}\right]_{i}$ was detected from the fura 2-acetoxymethyl ester (Fura 2-AM) 380/340 nm fluorescence ratio (F340/F380). In (A and B), data are expressed as fold increase over those of control cells. Bars represent the mean \pm SD. *Significant difference between the Fe-NTA and Fe-NTA+NaHS groups (P<0.05). (C) HSC-T6 cells were treated with NaHS, Fe-NTA or Fe-NTA+NaHS for $24 \mathrm{~h}$. Untreated cells served as healthy controls. Whole hepatic cell extracts were immunoblotted with the indicated antibodies. The expression of collagen I was detected in cells from healthy controls (lane A) and cells treated with NaHS (lane B), Fe-NTA (lane C) or Fe-NTA+NaHS (lane D) by western blot analysis. (D) The density of each band was measured and compared to that of the internal control, $\beta$-actin. Results are expressed as the means $\pm \mathrm{SD}$. Collagen I expression was significantly higher in the Fe-NTA group than in the normal group (P<0.05, $\mathrm{n}=12$ ). Treatment with NaHS decreased the Fe-NTA-induced collagen I expression $(\mathrm{P}<0.05, \mathrm{n}=12)$. Each bar represents the mean $\pm \mathrm{SD}$ for 12 animals. ${ }^{*} \mathrm{P}<0.05$ vs. control group; ${ }^{\#} \mathrm{P}<0.05$ vs. the Fe-NTA group $(\mathrm{n}=12)$.

NaHS decreases ROS generation in HSC-T6 cells. To determine whether NaHS is able to influence ROS generation in the Fe-NTA-induced HSC-T6 cells, the fluorescent probe, DCFHDA, was used to measure the levels of ROS. The intracellular ROS level was significantly higher in the HSC-T6 cells treated with Fe-NTA for 1, 3 (peak) and $6 \mathrm{~h}$ than in the control cells (Fig. 2A). NaHS alone did not influence ROS levels; however, it significantly reduced ROS levels in the Fe-NTA-treated cells at all time points $(\mathrm{P}<0.05)$.

NaHS increases cytoplasmic $\mathrm{Ca}^{2+}$ levels in HSC-T6 cells. To determine whether NaHS influences the levels of $\left[\mathrm{Ca}^{2+}\right]_{\mathrm{i}}$, Fura 2-AM staining was performed. The Fe-NTA treatment increased the fluorescence ratios (F340/F380) of the HSC-T6 cells to $159.7 \pm 24.5 \%(3 \mathrm{~h})$ and $187.7 \pm 28.7 \%(6 \mathrm{~h})$ of those of the control cells (Fig. 2B). Moreover, NaHS decreased cytoplasmic $\mathrm{Ca}^{2+}$ in the Fe-NTA-induced cells. NaHS alone did not change cytoplasmic $\mathrm{Ca}^{2+}$.

NaHS decreases collagen I protein expression in HSC-T6 cells treated with Fe-NTA. To further explore the effects of NaHS on collagen degradation in HSCs, the collagen I protein levels were determined by western blot analysis. Compared with the control group, the Fe-NTA treatment significantly increased the levels of collagen I protein in the HSC-T6 cells. In the cells treated with Fe-NTA and NaHS together, the collagen I protein levels were significantly lower than in the cells treated with Fe-NTA alone ( $<<0.05$; Fig. $2 \mathrm{C}$ and D).

$\mathrm{H}_{2} \mathrm{~S}$ attenuates $\mathrm{CCl}_{4}$-induced liver fibrosis. The blue pixels in the images of the liver sections from the rats with
$\mathrm{CCl}_{4}$-induced fibrosis that were injected with saline were significantly stronger than those from the healthy controls (Fig. 3A and B). However, the images of the liver sections from the rats with $\mathrm{CCl}_{4}$-induced fibrosis that were injected with NaHS had fewer blue pixels (Fig. 3C) than those from the saline-injected fibrotic rats. The numbers of blue pixels in the images of the liver sections were measured to quantify cell numbers. $\mathrm{CCl}_{4}$ significantly increased the number of blue pixels in the images of the liver sections, but NaHS significantly reduced the number of blue pixels compared with saline (Fig. 3D). We further measured collagen I, a marker of fibrosis, by immunohistochemical analysis. The staining intensity was significantly stronger in the $\mathrm{CCl}_{4}+$ saline group than in the control group (Fig. 4A and B). However, NaHS treatment lowered the staining intensity in the $\mathrm{CCl}_{4}$-treated rats (Fig. 4C). Quantification analysis demonstrated that the quantities of collagen $\mathrm{I}^{+}$cells were significant increased in the $\mathrm{CCl}_{4}$-treated rats compared with the healthy controls. NaHS treatment decreased the quantities of collagen $\mathrm{I}^{+}$cells in the $\mathrm{CCl}_{4}$-treated rats (Fig. 4D).

\section{Discussion}

In the present study, we found that $\mathrm{NaHS}$, a bioactive compound that releases $\mathrm{H}_{2} \mathrm{~S}$, suppressed the proliferation and cell cycle progression and induced the apoptosis of HSCs. The underlying mechanisms may be related to decreases in the levels of intracellular ROS, free calcium and collagen I protein expression. The effects of NaHS were also preliminarily confirmed by its ability to attenuate liver fibrosis and reduce collagen I protein expression levels in $\mathrm{CCl}_{4}$-induced rats. 

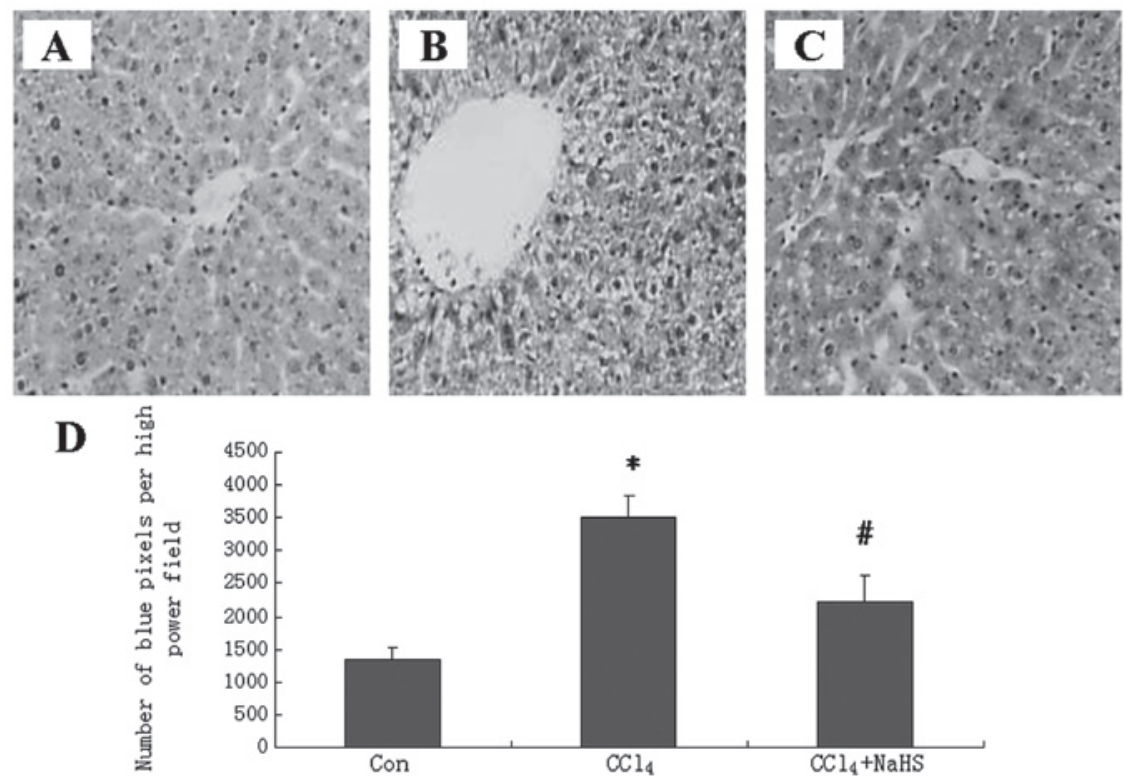

Figure 3. Histology of liver fibrosis. Representative images (magnification x400) of hematoxylin and eosin (H\&E)-stained liver sections from (A) healthy controls or rats treated with (B) carbon tetrachloride $\left(\mathrm{CCl}_{4}\right)+$ saline or $(\mathrm{C}) \mathrm{CCl}_{4}+$ sodium hydrogen sulfide (NaHS), for 6 weeks. (D) The numbers of blue pixels in each image of the H\&E-stained liver sections were counted and the average number per liver was calculated. Data are expressed as the mean \pm SD. There were 12 samples in each group. "Significant difference compared with the healthy controls. ${ }^{\#}$ Significant difference compared with the saline $+\mathrm{CCl}_{4}$-treated rats.
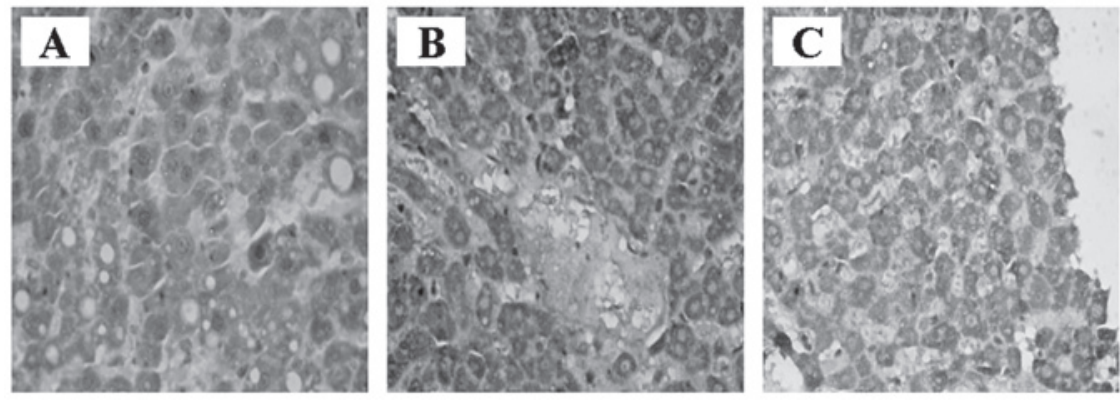

D

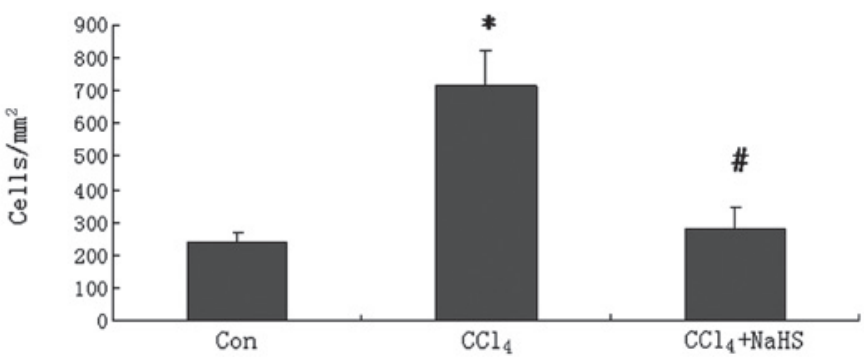

Figure 4. Immunohistochemical analysis of collagen I. Positive cells were labeled brown in the cytoplasm. Representative images (magnification $\mathrm{x} 400$ ) of liver sections taken from (A) healthy controls and rats treated with (B) carbon tetrachloride $\left(\mathrm{CCl}_{4}\right)+$ saline or $(\mathrm{C}) \mathrm{CCl}_{4}+$ sodium hydrogen sulfide (NaHS), for 6 weeks . The staining intensity was significantly stronger in the $\mathrm{CCl}_{4}+$ saline group than in the control group. NaHS treatment lowered the staining intensity in the $\mathrm{CCl}_{4}$-treated rats $(\mathrm{P}<0.05)$. (D) Quantification analysis demonstrated significant increases in the quantities of collagen $\mathrm{I}^{+}$cells in the $\mathrm{CCl}_{4}$-treated rats compared with the healthy controls. NaHS treatment decreased the quantities of collagen $\mathrm{I}^{+}$cells in the $\mathrm{CCl}_{4}$-treated rats. Data are expressed as the mean $\pm \mathrm{SD}$. There were 12 samples in each group. "Significant difference compared with the healthy controls. " Significant difference compared with the saline $+\mathrm{CCl}_{4}-$ treated rats.

HSC activation plays a central role in hepatic fibrosis and is accelerated by a self-amplification effect. Therefore, the inhibition of HSC activation is the focus of hepatic fibrosis treatments. HSC-T6 is an immortalized rat liver stellate cell line showing an activated phenotype of HSCs and a fibroblastlike morphology, and is often used in the investigation of hepatic fibrosis (12). In our study, we found that exogenous $\mathrm{H}_{2} \mathrm{~S}$ suppressed the proliferation of HSC cells in a dose-dependent manner, which may be caused by G1 phase cell cycle arrest and enhanced apoptosis in the NaHS-treated HSCs.

Intracellular ROS and oxidative stress contribute significantly to the activation of HSC and hepatic fibrosis (13). The overproduction of ROS results in oxidative stress, which is a link between chronic liver injury and hepatic fibrosis (14). Iron 
deposition is another characteristic of hepatic fibrosis which may either directly activate HSC or lead to lipid peroxidation (15). In the current study, we applied Fe-NTA to HSC cells to simulate oxidative stress conditions. The Fe-NTA treatment increased intracellular ROS levels and this increase was attenuated by NaHS, indicating that an antioxidation effect may participate in the inhibition of activated HSC cells. $\mathrm{H}_{2} \mathrm{~S}$ has previously demonstrated a protective effect through the inhibition of oxidative stress in the rat gastric mucosal epithelium (16).

The increased contractility of HSCs promotes fibrosis by regulating sinusoidal blood flow and ECM remodeling (17), which is mediated by $\mathrm{Ca}^{2+}$-dependent signaling pathways (18). The inhibition of $\mathrm{Ca}^{2+}$ signaling in HSCs contributes to the attenuation of hepatic fibrosis (19). Our results revealed that Fe-NTA increased intracellular $\mathrm{Ca}^{2+}$ levels in the HSC-T6 cells and that these levels were decreased by NaHS. Since Fe-NTA induces oxidative stress in HSC-T6 cells, this indicates that there is a positive correlation between intracellular ROS and $\mathrm{Ca}^{2+}$ levels in HSCs. This hypothesis is supported by a previous study in which a retinoic acid derivative downregulated ROS generation and calcium influx simultaneously in HSC-T6 cells and also reversed early liver fibrosis (20).

The increased synthesis and decreased degradation of the ECM is important in the pathophysiology of liver fibrogenesis, leading to overproduction and deposition of ECM in the liver. The ECM is mainly composed of type I and type III collagen, which are produced primarily by HSCs (21). In our study, $\mathrm{NaHS}$ decreased the intracellular $\mathrm{Ca}^{2+}$ levels in the HSC-T6 cells which indicates it may also affect ECM remodeling. We further found that NaHS significantly decreased type I collagen protein in Fe-NTA-induced HSC-T6 cells. Activated and proliferative HSC is the main cause for the ECM protein deposition that forms scar tissue during liver fibrogenesis. Our results demonstrated that NaHS not only inhibits the proliferation and activation of HSC, but also attenuates ECM remodeling.

To further confirm the antifibrotic effect of NaHS in vivo, we established a hepatic fibrosis model by the intraperitoneal injection of $\mathrm{CCl}_{4}$ to rats. $\mathrm{CCl}_{4}$ has been widely used as a chemical agent to induce hepatic fibrosis, and it is metabolized into trichloromethyl radicals which lead to increased lipid peroxidation, depletion of GSH and necrosis of hepatocytes (22). The present study demonstrated that the administration of NaHS attenuated $\mathrm{CCl}_{4}$-induced hepatic fibrosis, as evidenced by the reduction in the number of HSCs and decreased expression of collagen I protein in liver tissues. This is in accordance with previous reports on the cytoprotective effects of $\mathrm{NaHS}$ against hepatotoxicity, liver cirrhosis and portal hypertension in rats (23). This suggests that NaHS is able to inhibit HSC proliferation and ECM synthesis in vivo and thus shows therapeutic promise for hepatic fibrogenesis. It has been reported that in rats with $\mathrm{CCl}_{4}$-induced hepatic fibrosis, $\mathrm{CCl}_{4}$ downregulated the expression of CSE, the major enzyme for $\mathrm{H}_{2} \mathrm{~S}$ production in the liver, and that NaHS did not change either hepatic CSE expression or $\mathrm{H}_{2} \mathrm{~S}$-producing activity (23). In our study, it appears that the injected $\mathrm{NaHS}$ released $\mathrm{H}_{2} \mathrm{~S}$ in the body and directly mediated its antifibrotic effect through the HSCs. It remains to be further investigated whether the in vivo function of NaHS is mediated by inhibition of proliferation, cell cycle arrest, induction of apoptosis and decreased intracellular ROS and $\mathrm{Ca}^{2+}$ levels in the HSCs of rats with hepatic fibrosis.

In conclusion, the present study demonstrates that NaHS suppresses the proliferation of HSC-T6 cells in a dose-dependent manner and induces $\mathrm{G} 1$ cell cycle arrest and apoptosis in Fe-NTA-induced HSC cells. It also attenuates $\mathrm{CCl}_{4}$-induced hepatic fibrosis and ECM expression. These findings suggest that exogenous $\mathrm{H}_{2} \mathrm{~S}$ has promise in the development of new therapeutic strategies for hepatic fibrosis.

\section{References}

1. Lanthier N, Horsmans Y and Leclercq IA: The metabolic syndrome: how it may influence hepatic stellate cell activation and hepatic fibrosis. Curr Opin Clin Nutr Metab Care 12: 404-411, 2009.

2. Tarrats N, Moles A, Morales A, García-Ruiz C, FernándezCheca JC and Marí M: Critical role of tumor necrosis factor receptor 1 , but not 2 , in hepatic stellate cell proliferation, extracellular matrix remodeling, and liver fibrogenesis. Hepatology 54: 319-327, 2011.

3. Li JT, Liao ZX, Ping J, Xu D and Wang H: Molecular mechanism of hepatic stellate cell activation and antifibrotic therapeutic strategies. J Gastroenterol 43: 419-428, 2008.

4. Łowicka E and Bełtowski J: Hydrogen sulfide $\left(\mathrm{H}_{2} \mathrm{~S}\right)$ - the third gas of interest for pharmacologists. Pharmacol Rep 59: 4-24, 2007.

5. Gao Y, Yao X, Zhang Y, Li W, Kang K, Sun L and Sun X: The protective role of hydrogen sulfide in myocardial ischemiareperfusion-induced injury in diabetic rats. Int J Cardiol 152: 177-183, 2011.

6. Ahmad FU, Sattar MA, Rathore HA, Abdullah MH, Tan S, Abdullah NA and Johns EJ: Exogenous hydrogen sulfide $\left(\mathrm{H}_{2} \mathrm{~S}\right)$ reduces blood pressure and prevents the progression of diabetic nephropathy in spontaneously hypertensive rats. Ren Fail 34: 203-210, 2012.

7. Zhang LM, Jiang CX and Liu DW: Hydrogen sulfide attenuates neuronal injury induced by vascular dementia via inhibiting apoptosis in rats. Neurochem Res 34: 1984-1992, 2009.

8. Fiorucci S, Distrutti E, Cirino G and Wallace JL: The emerging roles of hydrogen sulfide in the gastrointestinal tract and liver. Gastroenterology 131: 259-271, 2006.

9. Kabil O, Vitvitsky V, Xie P and Banerjee R: The quantitative significance of the transsulfuration enzymes for $\mathrm{H}_{2} \mathrm{~S}$ production in murine tissues. Antioxid Redox Signal 15: 363-372, 2011.

10. Siebert N, Cantré D, Eipel C and Vollmar B: $\mathrm{H}_{2} \mathrm{~S}$ contributes to the hepatic arterial buffer response and mediates vasorelaxation of the hepatic artery via activation of K(ATP) channels. Am J Physiol Gastrointest Liver Physiol 295: G1266-G1273, 2008.

11. Ebrahimkhani MR, Mani AR and Moore K: Hydrogen sulphide and the hyperdynamic circulation in cirrhosis: a hypothesis. Gut 54: 1668-1671, 2005.

12. Vogel S, Piantedosi R, Frank J, Lalazar A, Rockey DC, Friedman SL and Blaner WS: An immortalized rat liver stellate cell line (HSC-T6): a new cell model for the study of retinoid metabolism in vitro. J Lipid Res 41: 882-893, 2000.

13. Ming-Ju H, Yih-Shou H, Tzy-Yen C and Hui-Ling C: Hepatitis C virus $\mathrm{E} 2$ protein induce reactive oxygen species (ROS)-related fibrogenesis in the HSC-T6 hepatic stellate cell line. J Cell Biochem 112: 233-243, 2011.

14. Ghatak S, Biswas A, Dhali GK, Chowdhury A, Boyer JL and Santra A: Oxidative stress and hepatic stellate cell activation are key events in arsenic induced liver fibrosis in mice. Toxicol Appl Pharmacol 251: 59-69, 2011.

15. Guo L, Enzan H, Hayashi Y, Miyazaki E, Jin Y, Toi M, Kuroda N and Hiroi M: Increased iron deposition in rat liver fibrosis induced by a high-dose injection of dimethylnitrosamine. Exp Mol Pathol 81: 255-261, 2006.

16. Yonezawa D, Sekiguchi F, Miyamoto M, Taniguchi E, Honjo M, Masuko T, Nishikawa $H$ and Kawabata A: A protective role of hydrogen sulfide against oxidative stress in rat gastric mucosal epithelium. Toxicology 241: 11-18, 2007.

17. Soon RK Jr and Yee HF Jr: Stellate cell contraction: role, regulation, and potential therapeutic target. Clin Liver Dis 12: 791-803, 2008 . 
18. Iizuka M, Murata T, Hori M and Ozaki H: Increased contractility of hepatic stellate cells in cirrhosis is mediated by enhanced $\mathrm{Ca}^{2+}$-dependent and $\mathrm{Ca}^{2+}$-sensitization pathways. Am J Physiol Gastrointest Liver Physiol 300: G1010-G1021, 2011.

19. Kim SY, Cho BH and Kim UH: CD38-mediated $\mathrm{Ca}^{2+}$ signaling contributes to angiotensin II-induced activation of hepatic stellate cells: attenuation of hepatic fibrosis by CD38 ablation. J Biol Chem 285: 576-582, 2010.

20. Yang KL, Chang WT, Chuang CC, Hung KC and Li EI: Antagonizing TGF-beta induced liver fibrosis by a retinoic acid derivative through regulation of ROS and calcium influx. Biochem Biophys Res Commun 365: 484-489, 2008.
21. Wells RG: Cellular sources of extracellular matrix in hepatic fibrosis. Clin Liver Dis 12: 759-768, 2008.

22. Weber LW, Boll M and Stampfl A: Hepatotoxicity and mechanism of action of haloalkanes: carbon tetrachloride as a toxicological model. Crit Rev Toxicol 33: 105-136, 2003.

23. Tan G, Pan S, Li J, Dong X, Kang K, Zhao M, Jiang X, Kanwar JR, Qiao H, Jiang H and Sun X: Hydrogen sulfide attenuates carbon tetrachloride-induced hepatotoxicity, liver cirrhosis and portal hypertension in rats. PLoS One 6: e25943, 2011. 